\title{
The use of bevacizumab in a multilevel retinal hemorrhage secondary to retinal macroaneurysm: a 39-month follow-up case report
}

This article was published in the following Dove Press journal:

Clinical Ophthalmology

12 October 2011

Number of times this article has been viewed

\author{
Dimitrios Tsakpinis' \\ Mayssa B Nasr ${ }^{1,2}$ \\ Paris Tranos ${ }^{3}$ \\ Nikos Krassas' \\ Theodoros Giannopoulos ${ }^{2}$ \\ Chrysanthos Symeonidis' \\ Stavros A Dimitrakos' \\ Anastasios GP Konstas ${ }^{2}$ \\ '2nd University Department of \\ Ophthalmology, Papageorgiou \\ Hospital; ${ }^{2}$ Glaucoma Unit, \\ Ist University, Department of \\ Ophthalmology, AHEPA Hospital, \\ Thessaloniki, Greece; ${ }^{3}$ Retina Eye \\ Center, Thessaloniki, Greece
}

Purpose: The evaluation of long-term visual outcome after the use of bevacizumab for the management of multilevel hemorrhage due to retinal arterial macroaneurysm (MA).

Case report: A 71-year-old hypertensive female presented with sudden reduction of visual acuity in her left eye (OS). Fundoscopy revealed an arterial macroaneurysm with preretinal and subretinal hemorrhage in the eye. Due to significant macular involvement, the patient received two intravitreal injections of bevacizumab within 2 months.

Results: Significant visual and anatomical recovery was observed 2 months later, which was confirmed by fluorescein angiography. At the end of a follow-up period (39 months) visual acuity and visual field were at normal levels.

Conclusion: Retinal MA is a relatively rare condition. Anti-vascular endothelial growth factor therapy appears a safe and effective treatment option for selected symptomatic individuals that may offer faster visual rehabilitation. Herein we report, for the first time, a 39-month follow-up of a retinal MA treated with anti-vascular endothelial growth factor therapy.

Keywords: arterial retinal macroaneurysm, anti-VEGF, bevacizumab, multilevel hemorrhage

\section{Introduction}

Retinal arterial macroaneurysms (MA) are localized fusiform or saccular vascular dilations occurring within the first three orders of bifurcation. ${ }^{1}$ Although most MA cases are usually quiescent and do not require intervention, others may lead to complications such as macular edema, retinal exudation, and multilevel retinal or intravitreal hemorrhage. ${ }^{2}$

Several therapeutic options have been proposed with varied visual outcome. ${ }^{1}$ Both bevacizumab and ranibizumab have been recently employed but with relatively limited follow-up. ${ }^{3-5}$ This is the first report of the use of anti-vascular endothelial growth factor (VEGF) agents specifically for MA therapy with sufficient long-term follow-up demonstrating significant functional and anatomical recovery.

\section{Case report}

A 71-year-old female was referred to the authors' unit with sudden reduction of visual acuity in her left eye (OS). Her past medical history included systemic hypertension and a successful surgical repair of a middle cerebral artery aneurysm 10 years ago. Best-corrected visual acuity was 0.8 in the right eye and 0.3 in the left. Anterior segment examination was unremarkable, revealing only mild bilateral nuclear lens opacities. Intraocular pressure was within normal limits in both eyes. Dilated 
fundoscopy showed an arterial MA along the superior temporal vascular arcades, accompanied by pre- and subretinal hemorrhage OS (Figure 1A and B). Fluorescein angiography revealed early filling with late leakage of the MA and significant masking due to a hemorrhage involving the macula (Figure $1 \mathrm{C}$ and D). Complete medical work up did not identify any other pathology (eg, diabetes mellitus), except systemic arterial hypertension. Her blood biochemical analysis was normal.

In view of the marked reduction in vision OS and because of her medical history, the patient received an intravitreal injection of bevacizumab (1.25 mg). One month after the first injection, visual acuity had improved to $0.4 \mathrm{OS}$, whereas dilated fundoscopy showed a partial resolution of the pre- and subretinal hemorrhage. Due to the rapid response to the anti-VEGF therapy and the improvement in visual acuity, a second bevacizumab injection (1.25 mg) was performed at this visit. Subsequently, 1 month later, visual acuity had improved to $0.5 \mathrm{OS}$ and fundoscopy examination revealed further resolution of fundus hemorrhage. This was also confirmed with angiography (Figure 2A-D). Four months later, visual acuity had improved to $0.8 \mathrm{OS}$ and fundoscopy exam showed an almost normal fundus with complete resolution of all hemorrhages. One year later, visual acuity remained stable at 0.8 OS and angiography revealed almost normal perfusion of the retina. At the final follow-up visit (39 months after diagnosis), vision remained at $0.8 \mathrm{OS}$ and a final fluorescein angiogram confirmed the complete absorption of hemorrhages, with normal perfusion of the previously affected retina (Figure 3A-D).

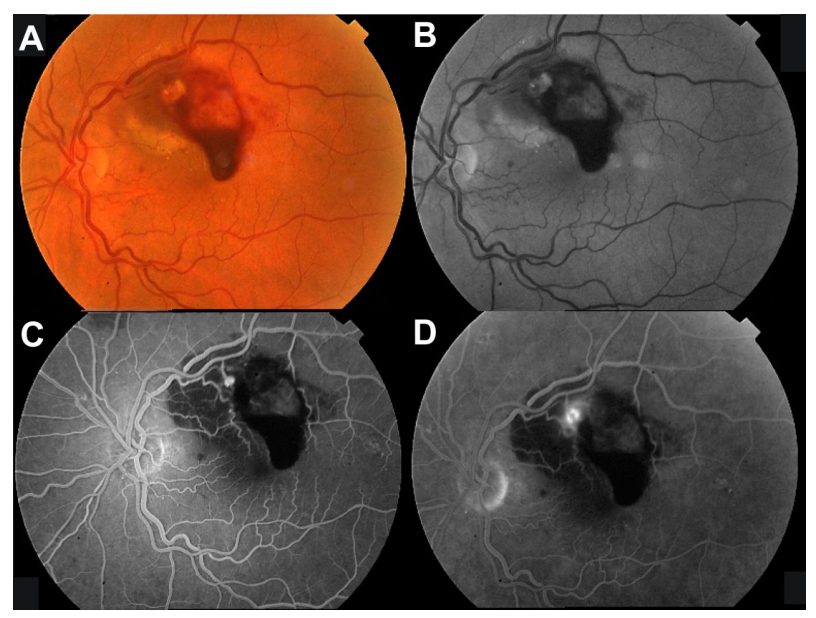

Figure I Color fundus photograph (A) and red-free photograph (B) of the left eye at baseline, showing multilevel hemorrhage due to a macroaneurysm. There is fluorescein filling of the macroaneurysm during the early phase $(\mathbf{C})$ and mild leakage during late phase (D).

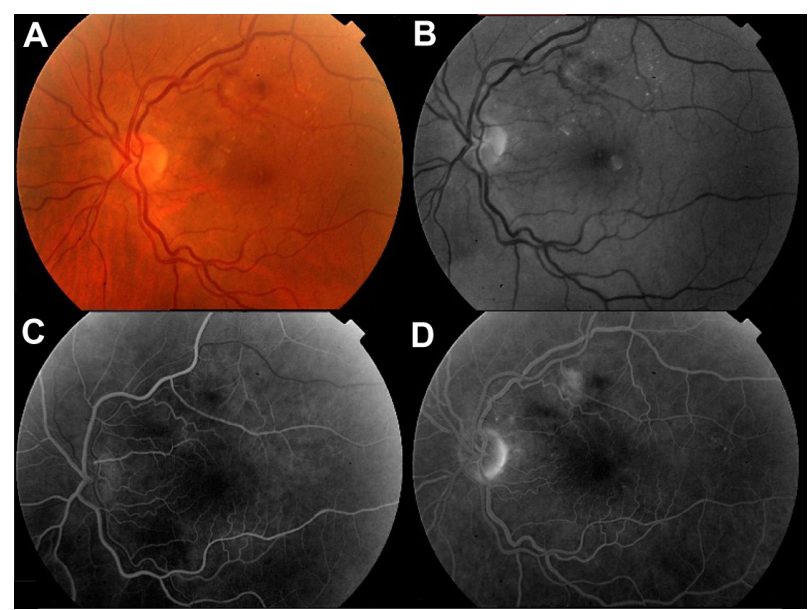

Figure 2 Two months later: color fundus photograph of the left eye $(\mathbf{A})$ and redfree photograph of the macroaneurysm (B) showing the fundus to be more normal, whereas early to midphase fluorescein angiogram (C) shows normal filling of the artery, and the later phase fluorescein angiogram (D) shows a substantial leakage.

\section{Discussion}

Retinal arterial MA is a relatively rare condition occurring in the course of hypertensive vascular disease, atherosclerosis, and retinal vein occlusion. ${ }^{1}$ It is usually associated with old age and has a female predominance $(60 \%-100 \%$ of reported cases). ${ }^{1}$ As in the case discussed, previous reports have documented a correlation between retinal arterial MA and the occurrence of cerebral arterial aneurysms, which are also more common in hypertensive females over 50 years of age. ${ }^{1}$

The pathogenesis of retinal MA is currently unknown. As arterioles age, intimal collagen replaces smooth muscle fibers, and the arterial wall becomes less elastic. These vessels are thought to be more susceptible to dilation

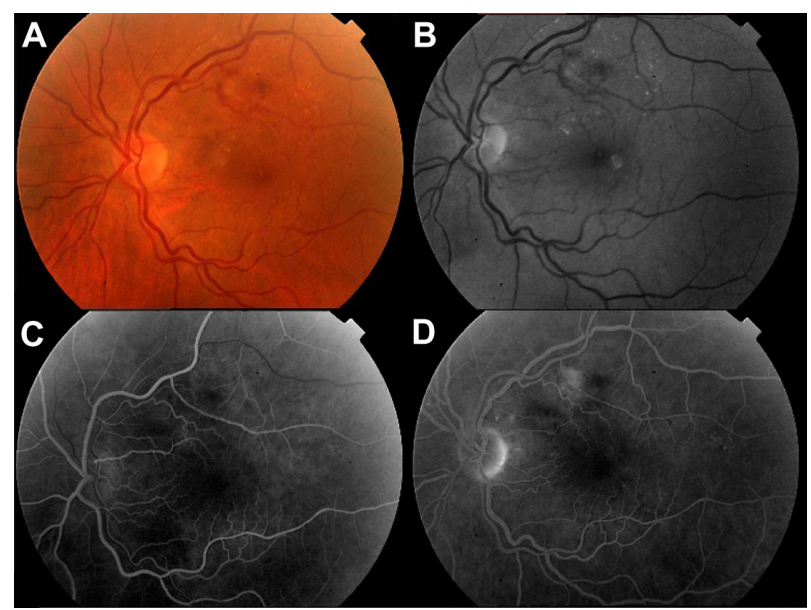

Figure 3 Thirty-nine months later: color fundus photograph of the left eye (A); redfree photograph (B); early (C) and late (D) phase of the fluorescein angiogram showing complete absorption of hemorrhage and resolution of the macroaneurysm leaving focal perivascular fibrosis. 
from elevated hydrostatic pressure. ${ }^{1,6}$ This phenomenon is more evident in hypertensive patients, who also experience elevated hydrostatic pressure, decreased autoregulation, and hyaline degeneration and are therefore especially at risk. ${ }^{1,6}$ Systemic hypertension has been implicated as a risk factor for exacerbation of several ocular ischemic disorders due to increased vascular permeability and intraocular neovascularisation, conditions that are primarily mediated by VEGF. Further, the increased mechanical stretch of the retinal endothelium, due to systemic hypertension, has been found to induce VEGF responses. ${ }^{7}$ This may also play a role in the formation of a MA; however, the precise pathogenetic cause of focal arterial wall weakness is not fully understood. In general, it is agreed that a MA occurs at arteriovenous crossings where the vessels are in contact without an adventitial layer, resulting in an area with less structural support. ${ }^{1,6}$

Therapeutic options for managing a MA vary without clear guidelines yet available. In general, it is agreed that this is usually a benign condition, which may resolve spontaneously with bleeding, because hemorrhage tends to thrombose the aneurysms that subsequently may lead to its involution. ${ }^{1}$ Thus, observation is thought to be sufficient in asymptomatic patients, where spontaneous involution is not unusual. ${ }^{6}$ For the same reason, symptomatic patients with a decrease in visual acuity due to vitreous or preretinal hemorrhage may be observed up to 6 months before any surgical intervention is made. ${ }^{6}$ In contrast, laser photocoagulation may be selected for an exudative MA, or surgical options may be chosen to manage multilevel bleeding, when there is macular involvement. This approach, however, is limited by several associated complications. ${ }^{4}$

Intravitreal injection of VEGF inhibitors, such as ranibizumab or bevacizumab, are more recent therapeutic alternatives, shown to reduce vascular permeability, normalize central retinal thickness and, consequently, lead to visual improvement. Since the development of retinal MA is associated with focal damage to arterial walls, leading to localized ischemia and VEGF upregulation, the use of anti-VEGF agents has been suggested as a means of achieving rapid resolution of the condition with a limited rate of complication. ${ }^{3-5}$
The patient discussed here presented with multilevel hemorrhage causing sudden reduction of visual acuity. Subretinal hemorrhage is thought to be toxic to retinal tissue, resulting in irreversible damage to photoreceptors and retinal-pigmented epithelial cells after 2 weeks. ${ }^{6}$ When MA is complicated by extensive multilayer bleeding involving the macula and threatening permanent loss of vision, VEGF injection may be selected to elicit faster absorption of subretinal bleeding. ${ }^{3-5}$ This was the course of action in this case. Importantly, the case discussed here furnishes some long-term evidence with a follow-up of 39 months following the intravitreal injection of bevacizumab. Rapid and almost complete resolution of the hemorrhages and significant visual recovery was observed, suggesting a successful and stable outcome. It is conceivable that besides macular edema the use of anti-VEGF may also be beneficial for multilevel hemorrhages associated with a retinal MA. Further investigation is required to confirm the outcome of this case in a larger series of MA patients and to establish the optimal treatment strategy.

\section{Disclosure}

The authors report no proprietary interest or financial support.

\section{References}

1. Contreras JE, Mittra RB, Mieler WF, Pollack JS. Retinal arterial macroaneurysms. In: Yanoff M, Duker JS, editors. Ophthalmology. 2nd ed. Philadelphia, PA: Mosby Elsevier; 2004:912-917.

2. Gamulescu MA, Helbig H. Vascular networks in retinal arterial macroaneurysms. Int Ophthalmol. 2009;29(2):91-93.

3. Wenkstern $\mathrm{AB}$, Peterson $\mathrm{H}$. Intravitreal ranibizumab in retinal macroaneurysm. Graefes Arch Clin Exp Ophthalmol. 2010;248(11): $1667-1670$.

4. Gallego-Pinazo R, Martínez-Castillo S, Arévelo JF, Díaz-Llopis M. Ranibizumab for retinal arterial macroaneurysm. Graefes Arch Clin Exp Ophthalmol. 2010;249(8):1267-1268.

5. Javey G, Moshfeghi AN, Moshfeghi AA. Management of ruptured retinal arterial macroaneurysm with intravitreal bevacizumab. Ophthalmic Surg Lasers Imaging. 2010;41(4):1-5.

6. Kester E, Walker E. Retinal arterial macroaneurysm causing multilevel retinal hemorrhage. Optometry. 2009;80(8):425-430.

7. Suzuma I, Hata Y, Clermont A, et al. Cyclic stretch and hypertension induce retinal expression of vascular endothelial growth factor and vascular endothelial growth factor receptor-2: potential mechanisms for exacerbation of diabetic retinopathy by hypertension. Diabetes. 2001;50(2):444-454.
Clinical Ophthalmology

\section{Publish your work in this journal}

Clinical Ophthalmology is an international, peer-reviewed journal covering all subspecialties within ophthalmology. Key topics include: Optometry; Visual science; Pharmacology and drug therapy in eye diseases; Basic Sciences; Primary and Secondary eye care; Patient Safety and Quality of Care Improvements. This journal is indexed on Submit your manuscript here: http://www.dovepress.com/clinical-ophthalmology-journal

\section{Dovepress}

PubMed Central and CAS, and is the official journal of The Society of Clinical Ophthalmology (SCO). The manuscript management system is completely online and includes a very quick and fair peer-review system, which is all easy to use. Visit http://www.dovepress.com/ testimonials.php to read real quotes from published authors. 